\title{
DESENVOLVIMENTO DE METODOLOGIA PARA EXTRAÇÃO DO ÓLEO DE ABACATE
}

\author{
G. B. HERMSDORFF ${ }^{1}$, V. P. de BRITO ${ }^{1}$ e V. S. AGUIAR ${ }^{1,2}$ \\ ${ }^{1}$ Faculdade de Engenharia de Sorocaba, FACENS \\ ${ }^{2}$ Universidade Estadual de Campinas, UNICAMP \\ E-mail para contato: gabrielahermsdorff@hotmail.com
}

\begin{abstract}
RESUMO - O óleo de abacate é muito utilizado na indústria de cosméticos devido suas propriedades hidratantes. $O$ processo de extração mais tradicional é o da prensagem a frio, que vem sendo substituída pela extração por solvente. $\mathrm{O}$ solvente mais utilizado é o hexano com a acetona, porém esse processo gera resíduos com elevado impacto ambiental. Portanto, formas alternativas e menos poluentes vêm surgindo, dentre elas a extração por enzima. Neste trabalho, buscou-se comparar esta extração com a extração por solvente, com o intuito de estudar o rendimento, bem como a análise composicional do óleo extraído.
\end{abstract}

\section{INTRODUÇÃO}

O abacate é um pseudofruto comestível, extensamente cultivado em regiões tropicais, inclusive no Brasil que é considerado um dos maiores produtores mundiais. Sua composição apresenta mais de $30 \%$ em gorduras, além de ser rico em açúcares e vitaminas (RAMALHO e SUAREZ, 2013).

O óleo de abacate possui altos teores de ácido oleico, que é um ácido graxo da classe de compostos orgânicos que constituem os lipídeos, os quais são vitais na construção da membrana celular. Ele é muito empregado em cremes e emulsões cosméticas pelas suas propriedades emolientes e para recompor a oleosidade em peles ressecadas. Também pode ser usado em bronzeadores e produtos solares devido a sua capacidade de proteção e regeneração da pele e queimaduras causadas pelos raios solares (UNIVERSIDADE FEDERAL DO RIO GRANDE DO SUL, 2015).

Entre os vários tipos de óleos funcionais, o de abacate é um dos mais benéficos para a saúde. Estudos científicos comprovam seus efeitos contra doenças cardiovasculares, câncer de próstata e diabetes (DANIELI, 2006).

Este trabalho teve como objetivo o desenvolvimento e a comparação de metodologias para realização da extração do óleo de abacate, investigando o método que reúna os melhores benefícios em termos econômicos e ambientais.

\section{METODOLOGIA EXPERIMENTAL}


O óleo de abacate é extraído quando os frutos estão maduros, isto é, com consistência amolecida, pois é neste estado que os frutos apresentam teores mais elevados de óleo.

Primeiramente, os abacates maduros foram despolpados, amassados e divididos em porções de $100 \mathrm{~g}$, conforme mostra a Figura 1. Em seguida, foram levados para a estufa para a desidratação em uma temperatura de $85{ }^{\circ} \mathrm{C}$, onde permaneceram por 120 horas até que a massa das amostras se tornasse constante. Após o período de estufa, todas as amostras foram colocadas em um dessecador para atingirem a temperatura ambiente, e na sequência, foram vedadas com parafilm.

Figura 1 - Porções das amostras de abacate.

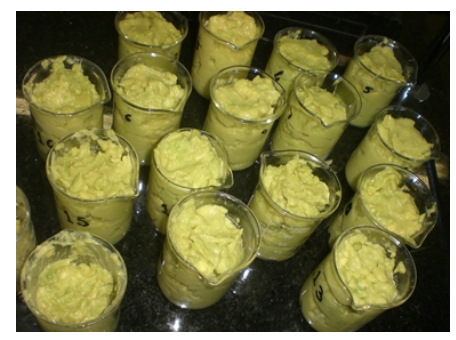

Para o método de extração por solvente foi preparada uma solução aquosa de ácido sulfúrico na concentração $0,5 \% \mathrm{v} / \mathrm{v}$. Colocaram-se $300 \mathrm{~mL}$ dessa solução em uma das amostras desidratadas na etapa anterior, para que ocorresse a hidrólise ácida. Esse sistema ficou sob agitação magnética por 60 minutos. Após esse período, deixou-se resfriar até que se atingisse uma temperatura de $30{ }^{\circ} \mathrm{C}$. A mistura obtida foi filtrada a vácuo e, para tanto, utilizou-se um funil de Büchner conectado a um kitassato, sobre o qual aplicou-se pressão reduzida. Em seguida, colocou-se a solução obtida em um funil de separação e adicionou-se $100 \mathrm{~mL}$ de hexano para que houvesse a extração do óleo, empregando a técnica de partição líquido-líquido. Após o descarte da fase aquosa, seguiu-se com a destilação simples da fase orgânica, obtendo-se o óleo bruto de abacate.

$\mathrm{Na}$ extração enzimática, foram adquiridos $30 \mathrm{~mL}$ da enzima Pectina Liase. Em seguida, foi adicionada água destilada a uma massa de amostra, na proporção $6: 1 \mathrm{v} / \mathrm{m}$, deixando agir por 5 minutos, após fervura. Essa solução teve seu pH ajustado até o pH ótimo de atuação da enzima ( $\mathrm{pH} 7,9)$. Adicionou-se a enzima em uma proporção $10 \% \mathrm{v} / \mathrm{m}$, que ficou sob agitação por 6 horas a $50{ }^{\circ} \mathrm{C}$. Após esse período, filtrou-se a mistura a vácuo e adicionou-se $20 \mathrm{~mL}$ de hexano à fase líquida coletada, deixando sob agitação por 45 minutos. Houve a destilação da fase hexânica e coleta do óleo bruto, como mostra a Figura 2.

Figura 2 - Óleo bruto obtido após destilação.

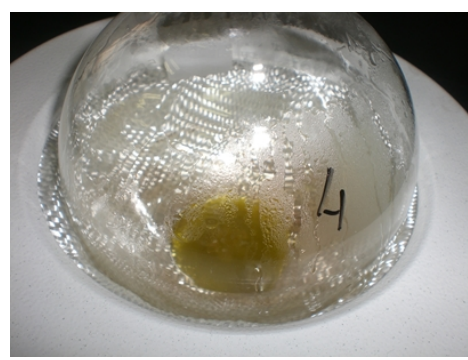


Para cada amostra foi feito o cálculo de rendimento, ou seja, o cálculo do teor de óleo extraído, por meio da Equação 1. Os valores de rendimento obtidos se encontram na Tabela 1, no tópico Resultados.

$$
[\text { óleo }]=\frac{\text { Massa }_{\text {óleo }}}{\text { Massa }}
$$

\section{RESULTADOS}

Uma importante evidência da qualidade do óleo de abacate é a quantidade de água presente na amostra. Em todas as amostras, realizou-se sua quantificação em aparelho Karl Fischer e os resultados obtidos se encontram na Tabela 1 (TANGO e CARVALHO, 2004).

A presença de ácidos graxos livres pôde ser avaliada pela especificação do índice de acidez. Índice de acidez fornece a indicação direta da presença de ácidos graxos livres e produtos de oxidação no óleo. Para sua quantificação, pesou-se 0,2000 $\mathrm{g}$ da amostra, adicionou-se 25,0 mL de solução tolueno: isopropanol: água $(1: 0,99: 0,01 \mathrm{v} / \mathrm{v} / \mathrm{v})$ e fez-se a titulação com solução alcoólica de hidróxido de potássio $0,100 \mathrm{~mol} \mathrm{~L}^{-1}$ até o alcance do ponto final. Os resultados obtidos também de encontram reunidos na Tabela 1.

Tabela 1 - Resultados das extrações do óleo de abacate.

\begin{tabular}{cccccc}
\hline Método & Amostra & $\begin{array}{c}\text { Rendimento } \\
(\%)\end{array}$ & Umidade $(\%)$ & $\begin{array}{c}\text { Teor de água } \\
(\%)\end{array}$ & $\begin{array}{c}\text { Índice de } \\
\text { acidez }(\%)\end{array}$ \\
\hline Hexano & 1 & 10,68 & 76,00 & 0,06 & 10,39 \\
(hidrólise & 2 & 9,59 & 75,69 & 0,11 & 7,81 \\
ácida) & 3 & 12,06 & 73,99 & 0,08 & 7,70 \\
\hline Éter de & 1 & 10,57 & 68,30 & 0,16 & 10,20 \\
petróleo & 2 & 8,89 & 68,40 & 0,33 & 10,44 \\
(hidrólise & 3 & 9,55 & 69,71 & 0,15 & 7,21 \\
ácida) & 1 & 11,22 & 74,66 & 0,33 & 7,19 \\
\hline Hexano & 1 & 10,06 & 67,41 & 0,47 & 7,62 \\
+ & 2 & 7,93 & 66,16 & 0,31 & 7,27 \\
Enzima & 3 & 8,25 & 64,79 & 0,23 & 8,02 \\
PL* & 1 & 10,06 & 66,91 & 0,79 & 7,88 \\
\hline Éter & 2 & 9,74 & 71,53 & 0,53 & 7,31 \\
+ & 3 & & &
\end{tabular}

*Pectina Liase

Também foi realizada a análise por infravermelho, cujos espectros das amostras de maior rendimento se encontram nas Figuras 3 e 4 . A Figura 5 contém o espectro do padrão de ácido oleico (ácido graxo em maior quantidade no óleo de abacate), para fins comparativos (LOPES e FASCIO, 2004). 
Figura 3 - Espectro de infravermelho da amostra que utilizou o hexano pelo método da hidrólise ácida.

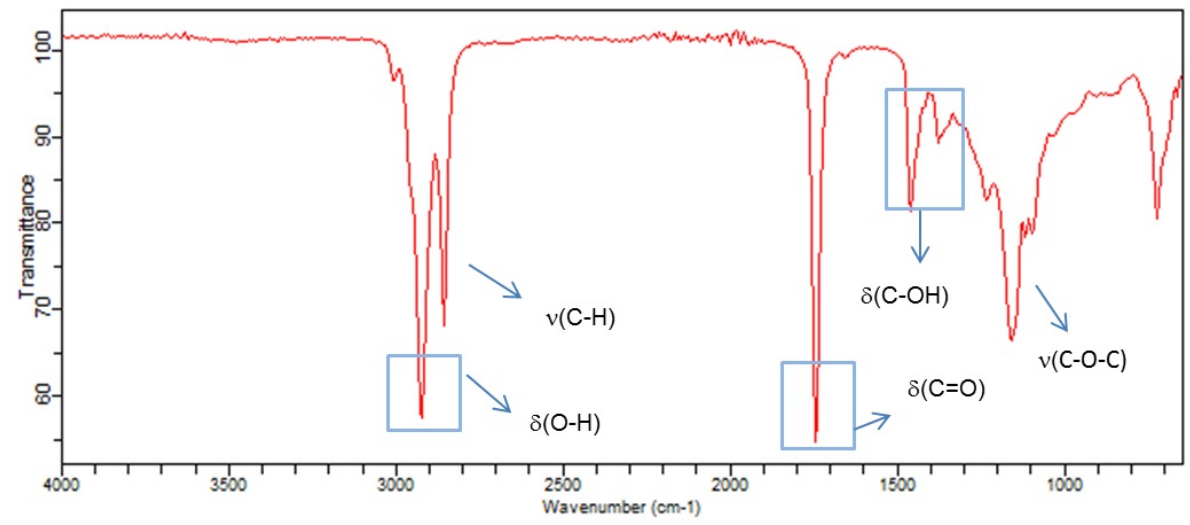

Figura 4 - Espectro de infravermelho da amostra que utilizou o hexano pelo método enzimático.

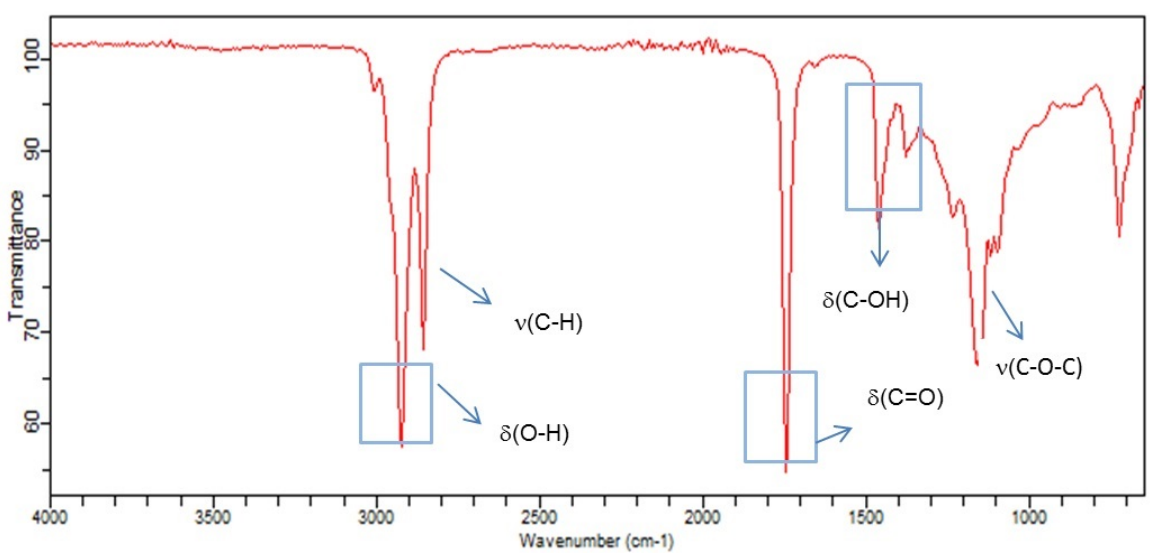

Figura 5 - Espectro de infravermelho do padrão de ácido oleico.

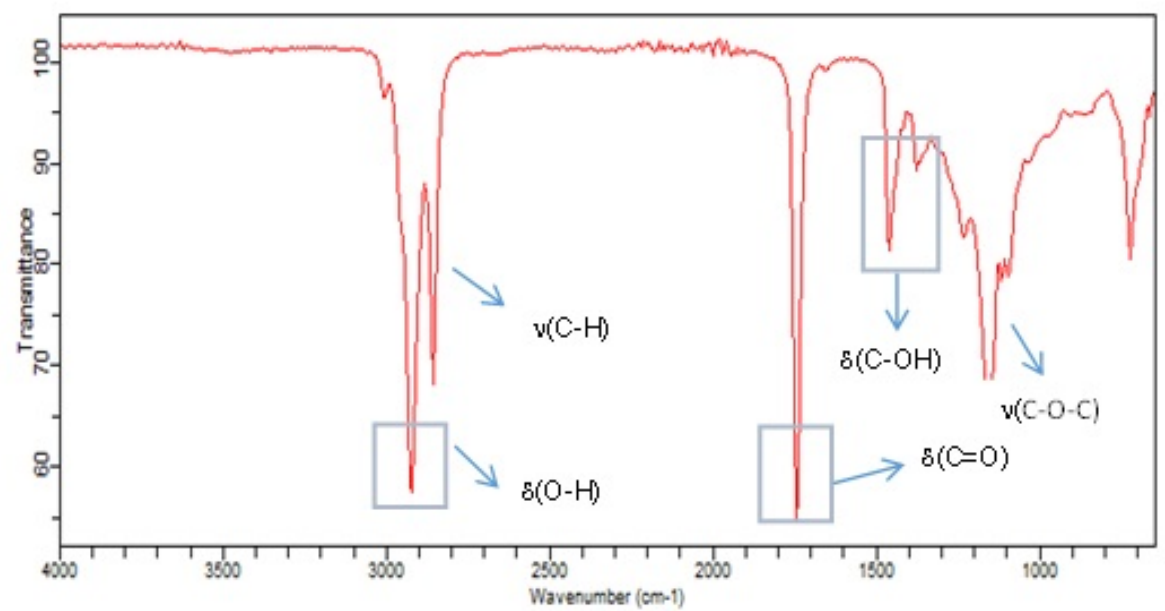




\section{CONSIDERAÇÕES FINAIS}

De acordo com os resultados apresentados, este trabalho procurou desenvolver e testar metodologias diferentes para efetuar a extração do óleo de abacate, por meio da extração com solvente e da extração com solução aquosa enzimática.

Foram avaliados os seguintes parâmetros: a quantidade de água presente nas amostras e a composição do óleo através de análises no Karl Fischer e por espectrometria de absorção no infravermelho. Analisando os espectros de infravermelho, notou-se uma alta similaridade entre as bandas características do padrão de ácido oleico e das amostras de óleo extraídas com hexano, por meio da hidrólise ácida e da solução aquosa enzimática, confirmando o alto teor do ácido graxo oleico na composição do óleo de abacate.

Por meio da análise do rendimento da extração e do teor de água, obtido através do método Karl Fischer, concluiu-se que o método mais eficaz, quantitativa e qualitativamente, foi a extração por hidrólise ácida, utilizando hexano como solvente. O método enzimático com éter de petróleo apresentou-se o menos eficiente, visto seu baixo rendimento, além de sua grande quantidade de água, observada tanto na análise de Karl Fisher quanto no espectro de infravermelho.

Portanto, pode-se concluir que o método enzimático foi menos eficiente que o método convencional de extração por solvente. E, considerando que o método por extração enzimática é aquele que reúne os maiores benefícios econômicos e ambientais, devido, por exemplo, ao reduzido gasto de solventes, estudos deverão ser desenvolvidos com o propósito de se alcançar resultados quantitativos satisfatórios (altos rendimentos e baixo teor de água agregada ao óleo) com a utilização das enzimas nos processos de extração do óleo de abacate.

\section{REFERÊNCIAS}

DANIELI, F. O óleo de abacate (Persea americana Mill) com uma matéria-prima para a indústria alimentícia. 2006. 48 p. Dissertação (Mestrado). Escola Superior de Agricultura Luiz de Queiroz, Universidade de São Paulo, Piracicaba, 2006.

LOPES, W.; FASCIO, M. Esquema para interpretação de espectros de substâncias orgânicas na região do infravermelho. Quim. Nova, v. 27, n. 4, p. 670-673, 2004.

RAMALHO, H. F.; SUAREZ, P. A. Z. A química dos óleos e gorduras e seus processos de extração e refino. Rev. Virtual Quim., v. 5, n. 1, p. 2-15, 2013.

TANGO, J. S.; CARVALHO, C. R. L.; SOARES, N. B. Caracterização física e química de frutos de abacate visando a seu potencial para extração de óleo. Rev. Bras. Fruticultura, v. 26, n. 1, p. 17-23, 2004.

UNIVERSIDADE FEDERAL DO RIO GRANDE DO SUL. Ácidos graxos. Disponível em: http://www.iq.ufrgs.br/ead/quimicapop/material/acidograxo.pdf Acesso em: 01 mar. 2015. 